\title{
The Uncommon Insight of Elinor Ostrom
}

\author{
Theodore C. Bergstrom \\ Department of Economics \\ University of California Santa Barbara
}

March 26, 2010 


\section{The Tragedy of the Commons}

Garrett Hardin invoked the metaphor of the tragedy of the commons as a call for collective action to reduce world population growth [11]

"Picture a pasture that is open to all. Each herdsman will try to keep as many cattle as possible on the commons... Therein is the tragedy. Each man is locked into a system that compels him to increase his herd without limit - in a world that is limited. Ruin is the destination toward which all men rush, each pursuing his own best interest in a society that believes in the freedom of the commons. Freedom in a commons brings ruin to all"

Economists find it natural to model Hardin's parable as a one-shot $n$ player game in which each player chooses the intensity with which he exploits the commons. The payoff to each player is an increasing function of his own exploitation but a decreasing function of the total exploitation by all $n$ players. Given plausible assumptions, such a game has a unique Nash equilibrium; and this equilibrium will be inefficient, since all players could be made better off if each reduced his exploitation.

More than a decade before Hardin's manifesto, H. Scott Gordon [10] formulated just such a model. Gordon's model was explicitly motivated by the economics of fisheries, but he suggested that it applies to many other economic activities, including drilling oil from a common pool, hunting and gathering, and the common pastures of the medieval manorial economy. Gordon pointed out that for Native American hunter-gatherers, access to fur-hunting territories was sometimes governed by a form of family ownership. He also noted that, according to historians, access to medieval common pastures was not unregulated, but subject to elaborate rules including limitations on numbers of animals and hours of pasturing. Thomas Schelling [32] suggested that the commons model also applies to pollution, infection, litter, and noise as well as to congestion of highways and other public facilities.

Studies of the commons problem have drawn inspiration from two competing traditions. The Pigovian approach [29] suggests that externalities may 
be dealt with by centrally imposed regulation and/or taxation calibrated to align private incentives with efficiency. The property rights approach is represented in the writings of Coase [3], Demsetz [6] [7], and Anderson and Hill [1], among others. These scholars argue that the most effective way to correct the inefficiencies that arise in common access problems is to eliminate common access and to establish marketable "property rights" with individual owners who have exclusive claim to the use of the relevant resources.

Elinor Ostrom pursues a third approach to study of the commons. The heart of Ostrom's method is to examine case studies of existing communities that have developed institutions suited to the particular technical problems that arise in their specific environments. Ostrom emphasizes that every realworld commons has its own peculiarities. She argues that actual commons problems are usually far more complex than the models that economists like to write down. Achieving efficiency by means of centrally imposed taxes or quotas will often be infeasible because central authorities misunderstand the local situation and because the participants have no incentive to reveal the information needed to achieve efficiency. The real-world commons problems that Ostrom studies usually involve repeated interactions among a relatively small number of players who are able to develop subtle institutions for monitoring and enforcing a degree of cooperation. In her book, Governing the Commons [19], she presents detailed observations of durable institutions for managing common pool resources. Some of these institutions have survived nearly intact for several hundred years. These examples include alpine pastures and forests communally owned by citizens of Swiss villages, communal meadows and forests in Japanese villages, and local irrigation reservoirs and ditches in Spain.

Ostrom attempts to identify common features of societies and institutions that promoted their efficacy and survival. She enumerates these "Design Principles Illustrated by Long-Enduring CPR institutions" as follows. ${ }^{1}$

1. Clearly defined boundaries, defining who can withdraw common re-

\footnotetext{
${ }^{1}$ This list appears in her 1990 book [19] (page 90) and also in her Journal of Economic Perspectives article [21].
} 
sources and who cannot. This feature makes the resources "common property" of insiders but does not allow "open access" to outsiders.

2. Appropriation rules that restrict time, place, technology, and/or quantity of resources withdrawn, where these rules are tailored to local conditions.

3. Collective choice rules that allow most individuals affected by rules to participate in any modification of these rules.

4. Monitoring of compliance, where the monitors are accountable to the local resource appropriators. Self-enforcement by group members is a critical feature of most successful solutions. Usually this works better than attempts to enforce rules passed by a an outside government that is ill-equipped to enforce these rules.

5. Graduated sanctions for non-compliance, where the severity of sanctions depend on the severity and context of the offense.

6. Access to rapid, low-cost arenas to resolve conflict among uses and between users and officials.

7. Minimal recognition of the right to organize by a national or local government.

8. For larger common pools, the presence of governance activities organized in multiple layers of nested enterprises.

Ostrom's research theme of the advantages of small-scale local organization over centralized agencies extends beyond common pool resource. For example, she has done interesting research in which she measures the output of local police forces more carefully than is usual. On this basis, she concludes that the claim that police forces enjoy economies of scale with specialization is not justified. She finds that locally controlled police forces function more effectively than branches of a large metropolitan police force.[27] 
Ostrom does not take a categorical or dogmatic position that local organizations will spontaneously produce satisfactory institutions. In [20], she states her position quite eloquently.

"What the research on social dilemma demonstrates is a world of possibility rather than of necessity. We are neither trapped in inexorable tragedies nor free of moral responsibility for creating and sustaining incentives that facilitate our own achievement of mutually productive outcomes. We cannot adopt the smug presumption of those earlier group theorists who thought that groups would always form whenever a joint benefit would be obtained. We can expect many groups to fail to achieve mutually productive benefits due to their lack of trust in one another or to the lack of arenas for low-cost communication, institutional innovation, and the creation of monitoring and sanctioning rules ... Without individuals viewing rules as appropriate ... no police force and court system on earth can monitor and enforce all the needed rules on its own."

\section{Property Rights and the Commons}

A central tenet of the property rights school is the so-called Coase Theorem. ${ }^{2}$ The basic claim of the Coase theorem is that in the absence of transaction costs, if property rights are clearly established, rational parties will necessarily achieve a Pareto-efficient allocation through voluntary areements. If we define transaction costs to be "all impediments to reaching a Pareto-efficient allocation through voluntary agreements," the Coase theorem can be interpreted as a simple tautology that focuses attention on the catch-all phrase transaction costs.

Adherents of the property rights school concede that because of transaction costs, it may not always be economical to establish individual property

\footnotetext{
${ }^{2}$ Coase himself did not claim a theorem. The phrase "Coase theorem" seems to have first appeared in George Stigler's Intermediate Microeconomics textbook. [36]
} 
rights. For herdsmen, the cost of fencing may make separate pastures uneconomical. The mobility of fish and wild game, and the difficulty of monitoring territorial restrictions, may make it impractical to enforce private property in hunting or fishing territories. Shopping centers may allow their parking lots to remain a commons because the cost of installing parking meters and enforcing compliance may make the sale of parking rights uneconomical. Coase, himself emphasized the importance of transaction costs in real world applications. In his 1991 Nobel prize lecture, Coase makes it clear that he does not regard creation of private property rights as a universal solution.

"Of course, it does not imply, when transaction costs are positive, that government actions (such as government operation, regulation or taxation, including subsidies) could not produce a better result than relying on negotiations between individuals in the market. Whether this would be so could be discovered not by studying imaginary governments but what real governments actually do. My conclusion: let us study the world of positive transaction costs." [4]

Much of Ostrom's work can be regarded as a response to Coase's call to "study the world of transaction costs" She shows how small-scale organizations have found ways to achieve near-efficiency without bearing the costs of fencing and enforcing property lines. But Ostrom also suggests that the impediments to Pareto-efficient agreement lie deep, and the notion of transaction cost is a slippery one. Often it is hard to know what it would mean to establish property rights. How does one go about "owning" a fish in the sea, flowing water, clean air, or a rapidly moving position on the freeway?

In Ostrom's words,

"It is difficult to know exactly what analysts mean when they refer to the necessity of developing private rights to some common pool resources. It is clear that when they refer to land, they mean to divide the land into separate parcels and assign individual rights to hold, use, and transfer these parcels... In regard to a 
fugitive resource, a diversity of rights may be established giving individuals rights to use particular types of equipment, to use the resource system at a particular time and place, or to withdraw a particular quantity of resource units (if they can be found). But even when particular rights are unitized, quantified, and salable, the resource system is still likely to be owned in common rather than individually." [19], page 13.

Ostrom and Schlager [33] suggest that it is useful to distinguish a variety of forms of partial property rights that may be attached to the use of commonpool resources. These include access (the right to enter a defined physical area), withdrawal (the right to extract resource units such as fish or water), management (the right to regulate use patterns), exclusion (the right to exclude others from access or withdrawal of resources), and alienation (the right to sell or lease management and exclusion rights.

In Governing the Commons [19], Ostrom describes many examples of arrangements that involve partial property rights. For centuries, peasant villagers in the Swiss Alps maintained private plots of land in the valley, where they produced cereal grains, fruit, and vegetables. In the summers, they pastured their cattle on communally owned alpine meadows. The laws of the village stated that "no citizen could send more cows to the alp than he could feed during the winter." Obligations for maintenance work on the summer pastures were divided among villagers in proportion to the number of cows they pastured. Mountain villages in Japan maintained common pastures and forests. The village assemblies created detailed rules restricting the time of harvesting wild plants, the allocation of jointly harvested hay, and the assignment of work effort to maintain the commons.

The irrigation canals in Spanish river valleys are maintained communally, and local groups impose complex rules regulating water withdrawal. The rules that govern many of these districts have been in place for 500 years. In ordinary times, farmers are assigned "turns" during which they may open their canal headgates. When his turn arrives, a farmer may take as much water as he wishes subject to not wasting water, and when he is finished he 
must close his headgates until the next time his turn arrives. In times of unusual drought, these procedures are modified to give priority to farmers whose crops are most in need of water.

Ostrom and Roy Gardner [25] report on a study of Nepalese irrigation districts that Ostrom organized [24]. This study encoded relevant features of 127 local systems. Of these systems, 86 were local farmer-managed organizations, and 22 were managed by government agencies. These systems faced a common technological feature. In the absence of some kind of agreement, farmers located upstream have first access to scarce irrigation waters, and farmers located downstream must make do with what is left. In the absence of agreement, farmers at the headwaters generally plant highly water-intensive rice crops, and land further downstream is essentially deprived of irrigation waters. Typically, this outcome is far from efficient. Where water usage is governed by local groups, the utilization rules are determined by bargaining among the farmers. Ostrom and Gardner argue that although those located upstream have superior bargaining power (since they have the option of unilaterally taking most of the water), contributions of labor by those who are located downstream is important to maintain the canal system, and thus groups are able to reach agreements that are more efficient and more favorable to downstream agriculture than the default outcome. The authors find that water districts that are managed by central government agencies perform less well than farmer-managed systems, where performance is measured by the fraction of water that reaches downstream users. They also argue that well-intentioned internationally financed projects to build durable headwater control systems and hence reduce maintenance costs may have been counterproductive because they reduced the demand for labor services supplied by downstream farmers.

In a chapter of [26], edited by Ostrom and coauthors, Edella Schrager reports the results of detailed studies of the assignment of rights in 33 organized groups who manage coastal fishing grounds. None of these groups assigned exclusive territorial rights to individuals. Almost all of these groups had residency rules restricting access to fishers who lived in a particular village or region. About two-thirds of these groups limited access to fishing grounds to 
those using particular technologies. About one-fourth of these groups prohibited catching fish below a specified minimum size. Some fisheries have developed ingenious rotation schemes for allocation of choice fishing spots over time. The institutional arrangements found in these case studies do not use mechanisms that would appear as first-best solutions in abstract models. In settings where economists might recommend per-unit charges for extraction or establishment of marketable quotas, the rules that are found tend to be limits on technological methods or date of extraction. According to Schrager,

"Little evidence suggests that coastal fishers themselves attempt to directly address appropriation externalities. It is surprising that there is no instance among this sample of coastal fishing grounds where fishers developed and used a quota rule allocating a quantity of fish to each fisher or fishing boat based on an estimate of the sustainable yield of fish. "([26], pages 264-265)

Ostrom and her coauthors argue that the methods that are in use may be more appropriate to the specific environments in which they are found, given the difficulties of monitoring, measurement, and enforcement.

Ostrom [19] recognizes that even if ownership of resources is easily defined and if there are no costs of drawing property lines or monitoring, there remain obstacles to reaching a Pareto-improving agreement. These are the incentive and information problems that bedevil those who bargain in the face of incomplete information. Ostrom cites the work of Mancur Olson [18], who emphasized the free-rider problems that arise in efforts to reach a multilateral agreements. The interests of small groups with concentrated interests are likely to be favored over those of larger groups with diffuse benefits. A simple model of voluntary multilateral agreements proposed by Dixit and Olson [8] suggests that even without conventional transaction costs, reaching an efficient social arrangement is far from automatic. This conclusion is supported by Ostrom's observations of many groups who fail to reach full efficiency. Informational barriers to achieving efficient agreements are not confined to cases with large number of agents. Myerson and Satterthwaite 
[17] show that difficulty arises even in the canonically simple situation of two parties who consider trading a single unit of an ordinary good. If each party has private information about his own valuation, they show that there is no incentive-compatible mechanism that guarantees a Pareto-improving trade with an efficient outcome. Mailath and Postlewaite [15] show that with incomplete information, under quite weak conditions, as the number of agents gets large, the probability of unanimous action to make a Pareto-improving change approaches zero.

\section{Commons and Anticommons}

Michael A. Heller [12] [13] has identified a class of social interactions that he calls the "tragedy of the anticommons." In contrast to the over-exploited common resources of Hardin's model, the resources in Heller's anticommons are under-exploited. This under-exploitation is not caused by an absence of property rights, but by the presence of "too many property rights" or perhaps more accurately, overly dispersed property rights. Heller cites many examples of inefficiencies that arise because owners or complementary factors are unable to reach efficient agreements. These include fragmented ownership of rights to the broadcast spectrum, of patents necessary for producing new products, of land needed for large projects, and of copyrights to music.

A recent discussion of the parallel tragedies of the commons and the anticommons by James Buchanan and Yong Yoon [2] points out that an anticommons problem was recognized by Adam Smith in The Wealth of Nations.

" The commerce besides which any nation can carry on by means of a river... which runs into another territory before it reaches the sea, can never be very considerable; because it is always in the power of the nations who possess that other territory to obstruct the communication between the upper country and the sea. The navigation of the Danube is of very little use to the different states of Bavaria, Austria, and Hungary, in comparison of what it would be if any of them possessed the whole of its 
course till it falls into the Black Sea. "( [35], bk. 1, ch. 3)

In 1838, long before the invention of modern game theory, A.A. Cournot [5] studied the "Nash equilibrium" outcome for a market with a small number of firms producing perfect substitutes and choosing their output quantities independently. In this case, as the number of competing firms increases, the equilibrium price declines and the total quantity sold increases. In the same treatise, Cournot analyzed a market in which the results are strikingly different. In this market, the firms produce complements rather than substitutes. Each firm is the sole supplier of a commodity used in fixed proportions as an input to produce some final good. Each input supplier sets his price independently so as to maximize his profits. As the number of independent sellers increases, the equilibrium price of the final good increases and the quantity decreases. Cournot illustrates this market with the parable of a copper monopolist and a zinc monopolist whose outputs are used entirely to produce brass, where the production of brass uses copper and zinc in fixed proportions. In Cournot's more familiar case of sellers of perfect substitutes, consolidation of ownership reduces social efficiency. In sharp contrast, for Cournot's complementary monopolists, consolidation of ownership increases social efficiency.

A natural question to ask in the case of Cournot's complementary monopolists is "why doesn't one of the input monopolists buy the others and offer the package of inputs at a price that maximizes total profits in the industry?" A similar question can be asked about land assembly for large urban projects. "If the value of an urban development exceeds the total value of the individual pieces of property to their current owners, why can't some entrepreneur assemble this land by voluntary purchases?" If the "Coase theorem" is true, why should democratic governments ever resort to eminent domain?

The following passage from Coase's Nobel lecture suggests that he recognized that land assembly may present significant "transaction costs."

"It is obviously desirable that these rights should be assigned to those who can use them most productively and with incentives 
that lead them to do so and that, to discover and maintain such a distribution of rights, the costs of their transference should be low, through clarity in the law and by making the legal requirements for such transfers less onerous...[T]his can come about only if there is an appropriate system of property rights and they are enforced..." [4]

It is not clear what mechanism Coase had in mind for "assigning" property rights. For example, one might read this passage as support for the use of eminent domain to consolidate land holdings whose ownership is currently dispersed. But even in the absence of considerations of justice and distribution, such a prescription does not explain how it could be determined who are "those who can use (the property rights) most productively".

Elinor Ostrom's strategy of studying the way that actual institutions deal with commons problems seems well suited for other social dilemmas, including the anticommons. Field studies of the anticommons are less common than those of the commons, but some nice examples can be found in the literature. Sometimes voluntary institutions have performed well in coordinating suppliers of complementary inputs. In other cases, it seems that coercion by a central authority has been the most effective.

Carl Shapiro [34] discusses the "patent thicket," an overlapping set of patent rights that require those who wish to commercialize new applications to obtain licenses from multiple patent holders. This problem is especially prevalent for applications in semiconductors, biotechnology, and computer software. Shapiro indicates that the problem is exacerbated by allowing overly strong rights to patent holders. He discusses instances in which firms have managed to partially solve the problem of overly dispersed property rights by means of cross-licensing agreements and patent pools. He also suggests that antitrust policy may be counterproductive because of its hostility towards cooperation among horizontal rivals.

Some of the most remarkable examples of cooperative provision of complementary inputs come from the open-source software movement, which has produced such products as the Linux operating system, LaTeX type- 
setting system, Firefox Web browser, and Apache server. In a collection of essays, The Cathedral and the Bazaar [31], Eric Raymond offers an insider's tour of the open source software movement. The essay entitled "The Magic Cauldron" provides insight into the way that peculiarities of software development have enabled programmers to achieve far greater efficiency than would be predicted by simple models of the tragedies of the commons and the anticommons.

Roy Gardner, Noel Gaston, and Robert Masson [9] discuss the history of toll collections on the Rhine river between Mainz and Cologne during the Middle Ages. Through much of this period, the Holy Roman Empire restricted the rights to collect tolls, limiting the number of separate toll collectors to about twelve. During the Interregnum of 1250-1273, the Holy Roman Empire lacked an emperor. Between 1250 and 1254, the number of local barons collecting tolls along this stretch of the Rhine approximately doubled, and the costs of navigating the river greatly increased. In 1254, a group of merchants and nobles of the region formed the Rheinische Bund, whose expressed goals were promoting the security of trade routes and suppression of "unjust" tolls. The Bund used military action to put the upstart robber barons and their castles out of business. Over the next three years, ten or eleven of the robber castles were deactivated. Although the Rheinische Bund was not stable and broke up after about three years, regional agreements remained in place to limit the number of toll collectors along the Rhine.

Edi Karni and Subir Chakrabarti [14] discuss the collection of taxes along the Silk Road, a trading route that extended from one oasis to the next all the way from China to the Mediterranean and over which trade was conducted for millenia. Control of the Silk Road was divided among many independent states, each of which imposed its on taxes on traders passing through. During some periods, large portions of the Silk Road were controlled by a single empire, and tax burdens on merchants were relatively low. In the ninth century, when the Han dynasty, which had controlled much of the eastern end of the Silk Road, was overthrown, the petty states along the Silk Road increased their taxes and the amount of trade diminished. 


\section{Game theory and Experiments}

Ostrom uses game theory adeptly and effectively in formulating and describing the problems that arise with common pool resources. She argues that in most of the interesting common pool resource problems, participants are engaged in a repeated game and there is no reason to expect outcomes to be well predicted by the Nash equilibrium for the one-shot version of the game that they play. Common pool resource situations are an especially appealing arena for the application of the theory of repeated games. In the case of irrigation, or pasturing, for example, every year is essentially a repetition of the previous year's conditions. As she emphasizes in the case of Swiss pasturing commons and Spanish irrigation systems, this repeated game has been played in a roughly constant environment for hundreds of years.

In Rules, Games $\&$ Common Pool Resources [26], Ostrom, Roy Gardner, and James Walker emphasize that although the folk theorem liberates players of repeated games from the necessity of repeating the one-shot Nash equilibrium, it gives almost no guidance of what to expect will happen in repeated pay. Repeated efficient action is only one of the great variety of outcomes that can be sustained by threats of punishment to deviators. Thus repeated game theory seems to issue a strong mandate for field studies of outcomes in actual communities.

In her 2005 book, Understanding Institutional Diversity [22], Ostrom emphasizes the importance of community norms as engines of achieving efficient social arrangements for common pool resources. She suggests that much as people have an evolved capacity to learn languages (see Pinker [30]), they seem to have an evolved capacity to learn certain kinds of norms. She suggests that there may be an evolutionary "grammar of norms" such that people learn at an early age to reciprocate good behavior and to resent and punish defection. She notes that parents try hard to teach these norms to their children, much as they do to teach language. She also points out that the content of norms varies from culture to culture, much as language does, and she discusses the evolutionary stability of norms.

Ostrom, Gardner, and Walker, [26] report on a series of laboratory exper- 
iments with repeated play of a common-pool resource extraction game. The experiments are cleanly designed implementations of the simple commonpool resource game that is familiar in economists' models. In these games, the Nash equilibrium outcome for the stage game is over-exploitation of the common pool.

They perform a series of alternative treatments of the basic commonpool game. In the initial treatment, there is no direct communication between players. Play proceeds with simultaneous moves in twenty consecutive rounds. They find that there is severe over-exploitation, much as is predicted by Nash equilibrium. However, the outcome does not settle on the Nash equilibrium and stay there, but instead there are "pulses" such that net yields are driven nearly to zero, followed by a period in which players reduce their exploitation and net yields rise, followed by another cycle of excess use and recovery.

Ostrom and her colleagues conduct a series of variations on this basic experiment. In one treatment, after ten rounds of play of the basic game, they announced that there would be several additional rounds and after each round, players would be able to sit in a circle and discuss the course of play and discuss how they would or should play in subsequent rounds. In these discussions, subjects typically discussed the optimal symmetric outcome and developed norms that if adhered to would result in optimal play. Although the communication was "cheap talk" in the sense that there was no direct method of enforcement of promises, subjects usually kept their promises to limit their exploitation of the common pool, and results were nearly optimal. The authors found that as the stakes were increased, the degree of cooperation that could be achieved in the communication treatment diminished, but remained substantial.

The authors also implemented "asymmetric" variations of this experiment in which some players had more resources to allocate than others. Less cooperation was found than in the symmetric case, but communication still led to a large increase in efficiency.

In another treatment, the authors replaced cheap talk communication with the ability to impose sanctions on players who overused the commons. 
The play of each subject was revealed to other players, and for a price, players were allowed to punish other players whose actions they disapproved of. This treatment produced much less efficient outcomes than the cheap talk communications treatment.

Ostrom demonstrates a subtle understanding of the strengths and weaknesses of formal modeling. While she is quite willing to use simplified abstract models to build understanding of the workings of a complex reality, she warns that

"The intellectual trap in relying entirely on models ... is that scholars then presume that they are omniscient observers able to comprehend the essentials of how complex, dynamic systems work by creating stylized descriptions of some aspects of these systems. With the false confidence of presumed omniscience, scholars feel perfectly comfortable in addressing proposals to governments that are conceived in their models as omnicompetent powers able to rectify the imperfections that exist in all field settings." [19] (p. 215)

\section{Political institutions and the commons}

Governing institutions that have successfully endured for many generations have managed to adapt their rules to changes in technology, in environmental factors, and in demographic factors. Ostrom maintains that in the long-lasting commons institutions she has observed, changes occurred in an orderly way according to predetermined collective choice and constitutional rules. She distinguishes between a set of "operational rules" that guide normal procedures and a set of "collective choice rules" that determine how to change operational rules and that are themselves determined according to "constitutional rules".

In addition to studying highly durable institutional solutions to commonvalue problems, Ostrom investigates the political process by which new institutions have been created to manage newly arisen common-pool problems. 
She discusses the development of rules for managing water extraction from three separate groundwater basins in the Los Angeles area in the early part of the twentieth century. Excessive use had reduced the amount of fresh water in these basins; as a result the intrusion of salt water threatened to make the water useless for human consumption. In each case, groups of local governments were ultimately able to cooperate in developing voluntary associations to manage water use. Ostrom argues that this bottom-up approach to organization by incremental steps is more likely to be successful than centrally imposed regulations.

Ostrom also studies several situations in which locally-developed common property institutions have failed; either producing highly inefficient outcomes or breaking down altogether. These failures include fisheries in Turkey, Sri Lanka, and Nova Scotia, groundwater basins in California, irrigation projects in Sri Lanka, and forests in Nepal. In these instances, Ostrom argues that local institutions, which had previously managed resource allocation relatively efficiently, failed in the face of changed technology and/or counterproductive intervention by national government regulations that failed to recognize the effectiveness of local governance.

\section{Global commons and local interaction}

In recent works, [23] [16], Ostrom attempts to apply the lessons learned from studies of cooperation in small-scale local groups to problems of global scope. In her words,

"Scholars have found that when groups are relatively small, engage in face-to-face communication, and build norms of trust and reciprocity, they are able to agree on a strategy to solve social dilemmas and carry through on agreements...A question is repeatedly posed as to whether it is actually possible to scale up to undertake global regulation of global economic problems such as global warming." [16], page 189 
Although she recognizes that "many contemporary environmental problems are larger than most nation states",[16] Ostrom advocates a polycentric approach to such problems as global climate change. She states that "while the effects of climate change are global, the causes are actions ... undertaken at a much smaller scale." [23] Moreover, she maintains that a great deal of progress could be made toward reduction of global pollution if small-scale communities are mobilized to act in their local interest. She cites as examples deforestation that may be the result of ill-defined property rights or of special-interest concessions granted by national governments that override more effective institutional arrangements that arise at the local level. She cites examples of cities and states around the world that have introduced local policies to reduce air pollution through emission controls, promotion of alternative energy, and reduction of automobile use. Ostrom suggests that lessons learned from small-scale societies about successful management of the commons may extend to agreements between participating agents, where the agents are representatives of entire countries.

\section{Conclusion}

On the day that Ostrom's Nobel prize was announced, economist Steven Levitt made the following remark in his blog, Freakonomics.

"If you had done a poll of academic economists yesterday and asked who Elinor Ostrom was, or what she worked on, I doubt that more than one in five economists could have given you an answer. I personally would have failed the test. ... I have no recollection of ever seeing or hearing her name mentioned by an economist. She is a political scientist, both by training and her career-one of the most decorated political scientists around. So the fact I have never heard of her reflects badly on me, and it also highlights just how substantial the boundaries between social science disciplines remain." 
In his New York Times column of October 9, 2009, economics Nobel Laureate, Paul Krugman, acknowledged that he was not familiar with her work. Professors Levitt and Krugman are both distinguished scholars with strong interests in the economics of public policy. The fact that they were unacquainted with Ostrom's work is, as Professor Levitt suggests, evidence of a remarkable lack of communication between subcultures of the academic world.

Whatever the cause of this gulf, I believe that for many economists, time invested in sampling Ostrom's writings will offer a good rate of return. For those who are willing to trek to the library, an efficient way to gain an overview of her methods and her achievements is to look through two of her books, Governing the Commons[19] and Rules, Games, \&6 Common Pool Resources. Those who cannot find their way to the library can get an informative glimpse of her work from reading [21] in the Journal of Economic Perspectives, her presidential address to the American Political Science Association in the American Political Science Review [20], and a description of her experimental work with economists, Roy Gardner and James Walker [28] in the American Political Science Review.

In many of Ostrom's papers, readers will find differences in style and substance from most papers written by economists. On matters of style, a feature of Ostrom's work that may seem alien to economists is the propensity of her papers to sprout taxonomic lists. This art form is not common in the economics papers that I read. I don't think economists are keen on lists, except possibly for lists of axioms. They are more accustomed to fiddling with mathematical models and squinting at regression coefficients. On matters of substance, Ostrom and her associates have collected and systematized field studies performed by dozens of authors who have studied hundreds of local institutions dealing with commons problems. These field studies have been conducted by historians, sociologists, anthropologists, forestry scientists, legal scholars, geographers, and economists. She has paralleled this field research with laboratory experiments (performed jointly with economists) for simulated common property environments. Her diligent pursuit of detailed case studies and her willingness to pay attention and respect to studies un- 
dertaken by scholars in other disciplines have served her well and should serve as a shining example to economists of the productivity of reaching beyond narrow disciplinary confines.

Ostrom sets her research in the context of reasonable economics models, but for the most part she does not develop the models as thoroughly as is the custom in economics. Theoretically inclined economists may wish to see more explicit models of the commons institutions that Ostrom observes. They may hope to see more detailed predictions and comparative statics. It would be desirable to have better predictions of the relationship between technological characteristics of a resource and the norms and systems of property rights that are likely to emerge. But we shouldn't expect one scholar, even a great scholar, to do everything. We should be pleased that Ostrom has left some work for the rest of us. Anyone with an interest in the economics of public policy and externalities will gain much from familiarity with her studies.

Although I confess to be as list-averse as the next economist, reading a large number of Ostrom's papers seems to have affected my writing style. I conclude with a list of reasons that economists should consider spending some time with her work.

1. They will learn much that is useful and interesting about institutions that manage common property resources.

2. They are likely to become more skeptical about simplistic solutions to social dilemmas like the tragedy of the commons.

3. They will see an example of how to integrate field research with cleanly designed laboratory experiments.

4. They will find a role model for incorporating work from other academic disciplines into their economic research.

5. They might learn to read lists all the way to the end. 


\section{References}

[1] Terry L. Anderson and Peter J. Hill. The not so wild, wild West. Stanford University Press, Stanford, CA, 2004.

[2] James Buchanan and Yong Yoon. Symmetric tragedies: Commons and anticommons. Journal of Law and Economics, 43(1):1-13, April 2000.

[3] Ronald Coase. The problem of social cost. Journal of Law and Economics, pages 1-44, 1960.

[4] Ronald Coase. The institutional structure of production. American Economic review, 82(3):713-719, June 1992.

[5] A. A. Cournot. Researches into the mathematical principles of the theory of wealth. Macmillan, originally published in French in 1838 edition, 1897.

[6] Harold Demsetz. The exchange and enforcement of property rights. Journal of Law and Economics, 7:11-26, October 1964.

[7] Harold Demsetz. Toward a theory of property rights. American Economic Review, 57(2):347-359, May 1967.

[8] Avanash Dixit and Mancur Olson. Does voluntary contribution undermine the coase theorem. Journal of Public Economics, 76(3):309-335, June 2000.

[9] Roy Gardner, Noel Gaston, and Masson Robert. Tolling the Rhine in 1254: Complementary monopoly revisited. Technical report, Workshop in Political Theory and Policy Analysis, Indiana University, Bloomington, Indiana, August 2002.

[10] H. Scott Gordon. The economic theory of a common-property resource: The fishery. Journal of Political Economy, 62(2):124-142, April 1954.

[11] Garrett Hardin. The tragedy of the commons. Science, 162:1243-1248, 1968. 
[12] Michael Heller. The tragedy of the anticommons: Property in the transition from marx to markets. Harvard Law Review, 111:621-688, 1998.

[13] Michael Heller. The Gridlock Economy. Basic Books, New York, 2008.

[14] Edi Karni and Subir Chakrabarti. Political structure, taxes, and trade. Journal of Public Economics, 64:241-258, 1997.

[15] George Mailath and Andrew Postlewaite. Asymmetric information bargaining problems with many agents. Review of Economic Studies, 57(3):351-367, July 1990.

[16] Michael McGinnis and Elinor Ostrom. Will lessons from small-scale social dilemmas scale up? In et al A. Biel, editor, New Issues and paradigms in research on social dilemmas, pages 189-211. Springer, 2008.

[17] Roger B. Myerson and Mark A. Satterthwaite. Efficient mechanisms for bilateral trading. Journal of Economic Theory, 29:265-281, 1983.

[18] Mancur Olson. The Logic of Collective Action. Harvard University Press, Cambridge, MA, 1965.

[19] Elinor Ostrom. Governing the Commons. Cambridge University Press, New York, 1990.

[20] Elinor Ostrom. A behavioral approach to the rational choice theory of collective action. American Political Science Review, 92(1):1-22, March 1998.

[21] Elinor Ostrom. Collective action and the evolution of social norms. Journal of economic perspectives, 14(3):137-158, Summer 2000.

[22] Elinor Ostrom. Understanding Institutional Diversity. Princeton University Press, Princeton, N.J., 2005. 
[23] Elinor Ostrom. A polycentric approach for coping with climate change. Technical report, Workshop in Political Theory and Policy Analysis, Indiana University, Bloomington, IN, 2009.

[24] Elinor Ostrom, Paul Benjamin, and Ganesh Shivakoti. Institutions, incentives, and irrigation in Nepal. Indiana University, Bloomington, Ind, 1992.

[25] Elinor Ostrom and Roy Gardner. Coping with asymmetries in the commons: Self-governing irrigation systems can work. Journal of Economic Perspectives, 7(4):93-112, Fall 1993.

[26] Elinor Ostrom, Roy Gardner, and Walker James. Rules, Games and Common-Pool Resources. University of Michigan Press, Ann Arbor, 1994.

[27] Elinor Ostrom, Roger Parks, and Charles Whitaker. Do we really want to consolidate urban police forces? A a reappraisal of some old asssumptions. Public Administration Review, 33:423-433, September/October 1973.

[28] Elinor Ostrom, James Walker, and Roy Gardner. Covenants with and without a sword. American Political Science Review, 86:404-417, June 1992.

[29] A.C. Pigou. The Economics of Welfare. MacMillan, London, 4th edition, 1932.

[30] Steven Pinker. The Language Instinct. W. Morrow, 1994.

[31] Eric S. Raymond. The Cathedral and the Bazaar. O'Reilly, Sebastopol, CA, 1999.

[32] Thomas Schelling. Micromotives and Macrobehavior. Norton, New York, 1978. 
[33] Edelle Schlager and Elinor Ostrom. Property rights regimes and natural resources. Land Economics, 68:249-262, 1992.

[34] Carl Shapiro. Navigating the patent thicket: Cross licenses, patent pools, and standard setting. In Innovation Policy and the Economy, Volume 1. National Bureau of Economic Research, Inc, December 2001.

[35] Adam Smith. The Wealth of Nations. W. Strahan and T. Cadell, London, 1776 .

[36] George J. Stigler. The Theory of Price. Macmillan, New York, third edition, 1966.

[37] Oliver Williamson. Transaction cost economics: The governance of contractual relations. Journal of Law and Economics, 22:233-261, October 1979.

[38] Oliver Williamson. The economics of governance. American Economic Review, 95(2):1-18, May 2005. 